\title{
An Empirical Study on the Impact of Environmental Regulation on the Efficiency of Green Technology Innovation
}

\author{
Wu $\mathrm{Min}^{1}$ \\ ${ }^{1}$ School of management of Tianjin University of Technology, Research center for circular economy and sustainable development of \\ enterprises, Tianjin 300384
}

\begin{abstract}
This paper uses two-stage super efficiency network SBM DEA model to calculate the efficiency of green technology innovation, and analyzes the spillover effect of three different environmental regulations, namely command control, market incentive and independent participation. The results show that the direct effect of the command control environmental regulation on the efficiency of green technology innovation is positive, the indirect effect and the total effect are negative; the direct effect, indirect effect and total effect of market incentive environmental regulation and independent participation Environmental Regulation on the efficiency of green technology innovation are positive.
\end{abstract}

\section{Introduce}

Under the background of the new normal economy, how to break through the constraints of resources and environment, and realize the transformation of industry from "blowing bubbles" to "squeezing water" is the focus of the current work, and improving the efficiency of green technology innovation of China's industry is the key link. The purpose of environmental regulation is to encourage or force industrial enterprises to improve the level of science and technology and pollution control ability, and promote the efficiency of green technology innovation. Then, in the face of the differences in the level of industrial development in different regions of China, how much contribution does different types of environmental regulations make to the efficiency of industrial green technology innovation in China? How to evaluate its promotion effect on the local and adjacent areas? How to adjust and use different types of environmental regulation policy tools? At present, there are few in-depth studies on it. Therefore, this paper first uses two-stage super efficiency network Sbm-dea model is used to measure the efficiency of industrial green technology innovation in China; then the environmental regulation is subdivided into three types: order control type, market incentive type and independent participation type, and the spatial panel model is used to demonstrate the spillover effect and size of different types of environmental regulation on the efficiency of industrial green technology innovation in this region and adjacent regions; Finally, the paper examines the differences between different regions in the choice of different types of environmental regulation.

\section{Model construction and variable description}

\subsection{GML (Global Malmquist Luenberger) index}

There are two defects in traditional $\mathrm{ml}$ index, which is to measure the non expected output index and compare the global with the global as the front. GML can solve the problem of ML index effectively. Based on the existing literature, the direction distance function is constructed, and the GML index from $t$ to $t+1$ is defined as follows:

$$
G M L^{+1}=\left[\frac{1+\vec{D}\left(x_{t+1}, y_{t+1}^{g}, y_{t+1}^{b}\right)}{1+\vec{D}\left(x_{t}, y_{t+1}^{g}, y_{t+1}^{b}\right)} \times \frac{1+\overrightarrow{D t+1}\left(x_{t+1}, y_{t+1}^{g}, y_{t+1}^{b}\right)}{1+\overrightarrow{D t+1}\left(x_{t}, y_{t+1}^{g}, y_{t+1}^{b}\right.}\right)^{\frac{1}{2}}
$$

Considering the externality of environmental regulation, ignoring the spatial correlation between regions and the resulting spillover effect, the research results will produce some deviation. Therefore, this paper uses the spatial panel model to study the impact of different types of environmental regulations on the efficiency of industrial green technology innovation in China. The spatial regression model was set as follows:

$$
y=\lambda W y+X \beta+W X \theta+\tau_{n} a+\varepsilon
$$

\subsection{Variable and data description}

For the selection of variables, referring to the research results of Xiao Renqiao et al. , Luo Liangwen and Liang Shengrong , nasierowski and arcellus, green technology innovation is divided into two stages: green technology research and development and green achievement transformation. Among them, the first stage of green 
technology R \&amp; D mainly considers two factors: human capital and capital input. The output is also the intermediate output, which is the input of the second stage. In addition to intermediate output, non R \&amp; D input and energy consumption are also inputs in the second stage. The output in the second stage includes expected output and unexpected output. The specific indicators of input and output in the two stages are shown in Table 1 on the following page. As R \&amp; D funds and new product development funds need time to accumulate, the relevant indicators are expressed by stock. Firstly, the relevant indicators are deflated to the 2006 price level according to the R \&amp; D price index, and then the inventory level over the years is calculated with the depreciation rate of $15 \%$ according to the perpetual inventory method. For the second stage of expected output, the sales revenue of new products and the total industrial output value are converted to the constant price level in 2006 by using the industrial GDP price index and the industrial product ex factory price index respectively. The treatment of environmental comprehensive index is to select five mixed indexes of industrial wastewater emission, industrial waste gas emission, industrial sulfur dioxide emission, industrial smoke and dust emission and industrial solid waste production per unit of industrial GDP, and give different weights to the five indexes by using entropy weight method, and finally get an environmental comprehensive index.

\subsection{Theoretical analysis}

On the relationship between environmental regulation and green technology innovation efficiency, the conclusion has not been unified. On the one hand, due to the strong cross-border mobility and negative externality of environmental pollution, various regions are faced with "free riding" behavior in the surrounding areas when implementing environmental regulation policies ${ }^{[1]}$. The policy behavior of the country or region makes the industrial enterprises choose to transfer the pollution to the areas with loose control when facing the environmental regulation, resulting in technology spillover and pollution transfer. Although this kind of zero sum game can reduce pollution in the short term, it may inhibit the improvement of green technology innovation efficiency in the long term ${ }^{[2]}$. On the other hand, in order to enhance the local competitive advantage, the local government forces the enterprises to transform and upgrade in the field of production technology through the implementation of environmental regulations. Reasonable environmental regulations achieve the "forced emission reduction effect" by offsetting the "compliance cost" through "innovation compensation" to promote the efficiency of green technology innovation ${ }^{[3]}$.

We need to improve. In view of the different research perspectives and methods of scholars, in order to get the impact of environmental regulation on the efficiency of green technology innovation ${ }^{[4]}$, it is more necessary to consider its spatial spillover. At present, the dominant mode of China's environmental regulation tools is from command and control type ${ }^{[3]}$, market incentive type and independent participation type to command and control type and market mechanism type

Incentive oriented, independent participation oriented transformation. Among them, the order control environmental regulation forces enterprises to improve the efficiency of resource utilization and reduce pollution emissions through the mandatory market rules formulated by the national administrative department, so as to improve the efficiency of green technology innovation; the market incentive environmental regulation can give enterprises more independent choices, and rely on the market's own regulatory mechanism to achieve the goal of pollution reduction to the maximum extent Independent participation environmental regulation indirectly promotes public awareness of environmental protection through public morality, public opinion and other means, relies on public power to promote environmental governance, and promotes enterprises to carry out green technology innovation

There is no formal legal regulation on environmental regulation. From the perspective of implementation characteristics, the implementation characteristics of different types of environmental regulation are also different. The three types of environmental regulation have the characteristics of technical compulsion, market flexibility and voluntary initiative respectively. From the perspective of implementation effect, the effective comprehensive system of different types of environmental regulation has not been established

The ideal implementation effect needs to be strengthened. Therefore, hypothesis 1 is proposed.

Hypothesis 1: different environmental regulation policies have different effects on the efficiency of green technology innovation.

Due to the differences in economic development level, geographical location, resources and environment, energy reserves and other factors, there are also great differences in the selection of environmental regulation types between the eastern and the central and western regions. Among them, the eastern coastal area has relatively strong strength, on the one hand, it can actively carry out pollution technology innovation, improve the input-output efficiency of the environment, on the other hand, it can comprehensively use different types of environmental regulations to improve the efficiency of industrial green technology innovation in the region, and the "innovation compensation" effect is fully reflected in the eastern region; however, the current central and western regions are far less than the eastern region This not only leads to the low efficiency of industrial green technology innovation, but also leads to the command control type of environmental regulation, which can not make full use of the advantages of different types of environmental regulation to improve the efficiency of industrial green technology innovation. In conclusion, hypothesis 2 is proposed.

Hypothesis 2: there is spatial heterogeneity in the choice of different types of environmental regulation in eastern, central and western regions. 


\section{Analysis of empirical results}

\subsection{Analysis on the efficiency of green}

technology innovation in China's industry.Based on the data from 2006 to 2017, this paper establishes a two-stage super efficiency network sbm-dea model, and decomposes the process of China's industrial green technology innovation into two stages: green technology R \& D and green achievements transformation. The total efficiency is the weighted average of the two stages. The results are shown in Table 1

Table 1 efficiency `of green technology innovation

\begin{tabular}{|c|c|c|c|c|}
\hline $\begin{array}{c}\text { Ranking of } \\
\text { regional }\end{array}$ & $\begin{array}{c}\text { R\&D } \\
\text { efficiency }\end{array}$ & $\begin{array}{l}\text { transformation } \\
\text { efficiency }\end{array}$ & $\begin{array}{c}\text { Total } \\
\text { efficiency }\end{array}$ & ranking \\
\hline Beijing & 0.6976 & 1.0218 & 1.7194 & 3 \\
\hline Tianjin & 0.5853 & 0.9108 & 1.4961 & 7 \\
\hline Hebei & 0.2818 & 0.5935 & 0.8753 & 21 \\
\hline Liaonign & 0.2698 & 0.5141 & 0.7839 & 22 \\
\hline Shanghai & 0.5055 & 0.8201 & 1.3256 & 10 \\
\hline Jiangsu & 0.6972 & 0.8402 & 1.5374 & 5 \\
\hline Zhejiang & 0.7666 & 0.7384 & 1.505 & 6 \\
\hline Fujian & 0.3719 & 0.83391 & 1.20581 & 11 \\
\hline Shandong & 0.4526 & 0.9311 & 1.3837 & 9 \\
\hline Guangdong & 0.8697 & 0.9294 & 1.7991 & 1 \\
\hline Hainan & 0.7136 & 1.0088 & 1.7224 & 2 \\
\hline East & 0.5648 & 0.8199 & 1.3847 & 8 \\
\hline Shanxi & 0.1486 & 0.3377 & 0.4863 & 33 \\
\hline Inner Mongolia & 0.1643 & 0.5711 & 0.7354 & 24 \\
\hline Jilin & 0.2685 & 1.2781 & 1.5466 & 4 \\
\hline Heilongjiang & 0.2323 & 0.2334 & 0.4657 & 34 \\
\hline Anhui & 0.6675 & 0.3786 & 1.0461 & 12 \\
\hline Jiangxi & 0.2652 & 0.6995 & 0.9647 & 17 \\
\hline Henan & 0.3604 & 0.6671 & 1.0275 & 13 \\
\hline Hubei & 0.4048 & 0.513 & 0.9178 & 18 \\
\hline Hunan & 0.5162 & 0.5067 & 1.0229 & 14 \\
\hline Guangxi & 0.2539 & 0.5123 & 0.7662 & 23 \\
\hline middle part & 0.3281 & 0.5486 & 0.8767 & 20 \\
\hline Chongqing & 0.4659 & 0.5396 & 1.0055 & 15 \\
\hline Sichuan & 0.5006 & 0.4111 & 0.9117 & 19 \\
\hline
\end{tabular}

\begin{tabular}{ccccc} 
Guizhou & 0.2804 & 0.243 & 0.5234 & 31 \\
Yunnan & 0.3511 & 0.3174 & 0.6685 & 26 \\
Shanxi & 0.3556 & 0.3393 & 0.6949 & 25 \\
Gansu & 0.2402 & 0.2727 & 0.5129 & 32 \\
Qinghai & 0.3255 & 0.3023 & 0.6278 & 28 \\
Ningxia & 0.1769 & 0.4178 & 0.5947 & 29 \\
Xinjiang & 0.2419 & 0.2822 & 0.5241 & 30 \\
\hline west & 0.3252 & 0.3408 & 0.666 & 27 \\
\hline Nationwide & 0.406 & 0.5733 & 0.9793 & 16 \\
\hline
\end{tabular}

Based on the national level, the overall level of China's industrial green technology innovation efficiency is low, and there is a huge room for improvement. Although China's environmental protection has been increasing in recent years and the waste of resources is gradually improving, the utilization efficiency still needs to be improved. Based on the regional level, the research and development of green science and technology, the transformation of green achievements and the total efficiency in the eastern, central and western regions are gradually decreasing. Relying on the advantages of economy, location, resources and policies, the eastern coastal areas have been at a high level in the field of technological innovation, while the extensive economic development mode of the central and western regions has not been effectively improved. Based on the provincial level, Guangdong, Hainan, Beijing and other provinces have a high level of green technology innovation efficiency. These provinces have a unique advantage in improving the efficiency of green technology innovation by virtue of the developed technology level and perfect market environment, while Xinjiang, Guizhou, Gansu and other provinces have a low score of green technology innovation efficiency, so they need to break through the efficiency bottleneck.

\subsection{Overall result analysis}

The randomness and fixity of space and time point are further tested, and the spatial Durbin model with double fixed space and time point is finally determined. In addition, considering the robustness of the results, the weight of adjacency and economic geography are selected for comparative analysis. The empirical results show that the direct effect, indirect effect and total effect of each variable are basically consistent under different spatial weights.

Table 2 Decomposition result of spatial effect based on geographical adjacency weight

\begin{tabular}{|c|c|c|c|c|c|c|}
\hline variable & \multicolumn{3}{|c|}{ Direct effect } & \multicolumn{3}{|c|}{ Indirect effect } \\
\hline PGDP & $\begin{array}{c}-0.085 \\
(-1.403)\end{array}$ & $\begin{array}{l}-0.166^{* *} \\
(-2.681)\end{array}$ & $\begin{array}{c}-0.0808 \\
(-1.2562)\end{array}$ & $\begin{array}{c}-0.146 \\
(-1.285)\end{array}$ & $\begin{array}{c}-0.285^{* * *} * \\
(-2.805)\end{array}$ & $\begin{array}{c}-0.186 \\
(-1.691)\end{array}$ \\
\hline $\mathrm{HC}$ & $\begin{array}{c}-0.050 * * * \\
(2.713)\end{array}$ & $\begin{array}{c}0.038 \\
(0.040)\end{array}$ & $\begin{array}{c}-0.042 * * \\
(2.275)\end{array}$ & $\begin{array}{c}0.030 \\
(0.939)\end{array}$ & $\begin{array}{c}0.055^{*} \\
(1.815)\end{array}$ & $\begin{array}{c}0.063^{*} \\
(1.606)\end{array}$ \\
\hline FS & $\begin{array}{c}-0.006 \\
(-0.179)\end{array}$ & $\begin{array}{c}-0.005 \\
(-0.191)\end{array}$ & $\begin{array}{c}-0.013 \\
(-0.354)\end{array}$ & $\begin{array}{l}-0.185 * \\
(1.719)\end{array}$ & $\begin{array}{c}-0.203 * * \\
(2.234)\end{array}$ & $\begin{array}{c}0.166 \\
(1.629)\end{array}$ \\
\hline
\end{tabular}




\begin{tabular}{|c|c|c|c|c|c|c|}
\hline ES & $\begin{array}{l}-0.003 * * \\
(-2.420)\end{array}$ & $\begin{array}{l}-0.007 * * \\
(-2.740)\end{array}$ & $\begin{array}{l}-0.025 * * \\
(-2.521)\end{array}$ & $\begin{array}{l}-0.041 * * \\
(-2.406)\end{array}$ & $\begin{array}{l}-0.035^{* *} \\
(-2.222)\end{array}$ & $\begin{array}{c}-0.002 * \\
(-1.836)\end{array}$ \\
\hline GS & $\begin{array}{c}-0.092 * * \\
(2.870)\end{array}$ & $\begin{array}{l}-0.006 \\
(-021)\end{array}$ & $\begin{array}{l}-0.005 * * \\
(-2.493)\end{array}$ & $\begin{array}{l}-0.004 * * \\
(-2.406)\end{array}$ & $\begin{array}{l}-0.035^{* *} \\
(-2.272)\end{array}$ & $\begin{array}{c}-0.002^{*} \\
(-1.836)\end{array}$ \\
\hline ML & $\begin{array}{c}-0.007 \\
(-0.530)\end{array}$ & $\begin{array}{l}-0.002 * \\
(-1.999)\end{array}$ & $\begin{array}{l}-0.008 \\
(-1.262)\end{array}$ & $\begin{array}{c}-0.165 \\
(-1.255)\end{array}$ & $\begin{array}{c}-0.282 * * * \\
(-2.852)\end{array}$ & $\begin{array}{l}-0.183 \\
(-1.691)\end{array}$ \\
\hline RFE & $\begin{array}{c}-0.0238^{* *} \\
(2.666)\end{array}$ & $\begin{array}{l}0.0231 * * \\
(2.5821)\end{array}$ & $\begin{array}{c}-0.008 \\
(-1.262)\end{array}$ & $\begin{array}{c}-0.175 \\
(-1.285)\end{array}$ & $\begin{array}{c}-0.952 * * * \\
(-2.802)\end{array}$ & $\begin{array}{c}-0.183 \\
(-1.641)\end{array}$ \\
\hline FDI & $\begin{array}{c}-0.0397 * * \\
(-2.677)\end{array}$ & $\begin{array}{l}0.0418 * * \\
(-3.053)\end{array}$ & $\begin{array}{l}-0.088 \\
(-1.262)\end{array}$ & $\begin{array}{c}-0.165 \\
(-1.855)\end{array}$ & $\begin{array}{c}-0.285^{* * *} \\
(-2.852)\end{array}$ & $\begin{array}{c}-0.183 \\
(-1.691)\end{array}$ \\
\hline CCER & $\begin{array}{c}0.056^{*} \\
(1.740)\end{array}$ & & & $\begin{array}{c}-0.597 * * * \\
(-4.415)\end{array}$ & & \\
\hline MIER & & $\begin{array}{c}0.2929 * * * \\
(3.0507)\end{array}$ & & & $\begin{array}{l}0.455^{* *} \\
(2.610)\end{array}$ & \\
\hline APER & & & $\begin{array}{l}0.0383 * \\
(1.802)\end{array}$ & & & $\begin{array}{c}0.232 * * * \\
(4.348)\end{array}$ \\
\hline
\end{tabular}

\section{3 analysis of regional results}

In view of the great differences among the eastern, central and western regions, this paper further verifies hypothesis 2 through empirical analysis, and the results are shown in Table 4. For the eastern region, the symbols of the three types of environmental regulation are consistent with the overall measurement results, which shows that the eastern region plays an important role in green technology innovation. However, the total effect of order control environmental regulation is negative, which is opposite to market incentive environmental regulation and self participation environmental regulation. It can be seen that although the eastern region has improved the efficiency of green technology innovation by virtue of relatively developed economic advantages, it still needs to optimize and improve the implementation form of order control environmental regulation. For the central region, the effect of command and control environmental regulation on the efficiency of green technology innovation is not significant, and can not play its role. For the western region, although the effect of command and control environmental regulation and market incentive environmental regulation is significant, the impact on the efficiency of green technology innovation is more reflected in inhibition. This is because all aspects of development in the central and western regions are relatively backward, and the lack of capital, human resources, science and technology makes the implementation of environmental regulation fail to play an effective role in industrial green technology innovation.

\section{Conclusion}

Based on the panel data of 30 provinces in China from 2006 to 2017, this paper uses the two-stage super efficiency network sbm-dea model to measure the efficiency of China's industrial green technology innovation, and uses the spatial Durbin model to analyze the impact of different types of environmental regulations on the efficiency of China's industrial green technology innovation. The main conclusions are as follows: environmental regulation has an impact on the efficiency of green technology innovation, in which the direct effect of command control environmental regulation on the efficiency of green technology innovation is positive, the indirect effect and the total effect are negative, and the direct effect, indirect effect and the total effect of market incentive environmental regulation and independent participation Environmental Regulation on the efficiency of green technology innovation are positive. Specific to different regions, the spillover effect of three types of environmental regulation in eastern and central regions is consistent with the overall measurement results, while the effect of command and control environmental regulation in western regions is opposite to the overall measurement results.

\section{References}

1. Song Yan,Li Zhenran,Liu Jun, Yang Tingting,Zhang Ming,Pang Jingru. The effect of environmental regulation on air quality in China: A natural experiment during the COVID-19 pandemic[J]. Atmospheric Pollution Research,12(2021)

2. Gao Jingzhe,Xiao Zhongdong,Wei Haixiao. Competition and coordination in a dual-channel green supply chain with an eco-label policy[J]. Computers \&amp; Industrial Engineering,153(2021)

3. Kokosalakis George,Merika Anna,Merika XakoustiAfroditi. Environmental regulation on the energyintensive container ship sector: A restraint or opportunity?[J]. Marine Policy,125(2021)

4. Ye Fang, Quan Yongbo,He Yixiong,Lin Xiaofang. The impact of government preferences and environmental regulations on green development of China's marine economy[J]. Environmental Impact Assessment Review,87(2021) 